\title{
Idiopathic Orbital Inflammation Appearing on the Affected Side of Preceding Myasthenia Gravis
}

\author{
Satoru Fujita ${ }^{1}$, Natsumi Furuta ${ }^{1}$, Tokuzo Maruyama ${ }^{1}$, Setsuki Tsukagoshi ${ }^{1}$, \\ Kazuaki Nagashima ${ }^{1}$, Yukio Fujita ${ }^{1}$, Kazuki Nagai ${ }^{2}$, Tomoyuki Kashima ${ }^{3}$, Makoto Tanaka ${ }^{4}$, \\ Izumi Miki ${ }^{5}$, Ayako Yamazaki ${ }^{6}$, Hayato Ikota ${ }^{6}$, Tetsunari Oyama ${ }^{6}$ and Yoshio Ikeda ${ }^{1}$
}

\begin{abstract}
:
The patient was a 70-year-old man with idiopathic orbital inflammation (IOI) that appeared on the severely affected side of preceding myasthenia gravis (MG). The patient was diagnosed with MG 5 years prior to the onset of IOI. When IOI was diagnosed, an edrophonium test was negative. IOI was considered because he complained of left orbital pain, eyelid swelling, and cerebral MRI exhibited the enhanced lesions along the left orbital periosteum. A biopsy specimen revealed pathological findings compatible with IOI. The administration of corticosteroids was effective for improving the ocular symptoms. IOI should be considered when ocular symptoms deteriorated with soft tissue swelling/pain in MG patients.
\end{abstract}

Key words: myasthenia gravis, idiopathic orbital inflammation, corticosteroid

(Intern Med 59: 1763-1767, 2020)

(DOI: 10.2169/internalmedicine.4235-19)

\section{Introduction}

Idiopathic orbital inflammation (IOI) is characterized by orbital mass lesions with nonspecific inflammation of unknown cause (1). Myasthenia gravis (MG) is an autoimmune disorder in which autoantibodies against acetylcholine receptor (AChR) and other components of the neuromuscular junction cause skeletal muscle weakness (2). Blepharoptosis or limited eye movement, which is commonly observed in patients with MG or IOI, may hamper the differential diagnosis of these disorders. This is a case report of a male patient with IOI that appeared on the severely affected side of preceding MG.

\section{Case Report}

The patient was a 70-year-old Japanese man who had been diagnosed with ocular-type MG. His initial symptoms started in July 2013 with blepharoptosis and diplopia due to limited abduction of the left eye. An edrophonium test improved his blepharoptosis and ocular disturbance, and pyridostigmine was administered from August 2013. His ocular symptoms were totally ameliorated without difficulty in daily living until October 2013.

In August 2018, the patient experienced orbital pain in his left eye. Two months later, progressive left eyelid swelling with blepharoptosis and diplopia was noted; subsequently, he was admitted to our hospital. The patient's serum antiAChR antibody titer increased to $27.7 \mathrm{nmol} / \mathrm{L}$. The patient's past medical history included sinusitis in childhood and spinal cord injury due to a fall, from which he had fully recovered. He also had hypertension.

A neurological examination revealed lateral and inferior gaze palsy, eyelid swelling, blepharoptosis, and proptosis in the left eye (Fig. 1). He did not experience diurnal fluctuation of his symptoms. The pupils were isocoric, and light reflexes were prompt in both eyes. Visual acuity, anterior eye

${ }^{1}$ Department of Neurology, Gunma University Graduate School of Medicine, Japan, ${ }^{2}$ Department of Ophthalmology, Gunma University Graduate School of Medicine, Japan, ${ }^{3}$ Shinmaebashi Kashima Oculoplastic Clinic, Japan, ${ }^{4}$ Department of Neurology, Shinozuka Hospital, Japan, ${ }^{5}$ Department of Medical Education, Showa University School of Medicine, Japan and ${ }^{6}$ Department of Diagnostic Pathology, Gunma University Graduate School of Medicine, Japan

Received for publication November 22, 2019; Accepted for publication February 12, 2020

Correspondence to Dr. Yoshio Ikeda, ikeday006@gunma-u.ac.jp 
A

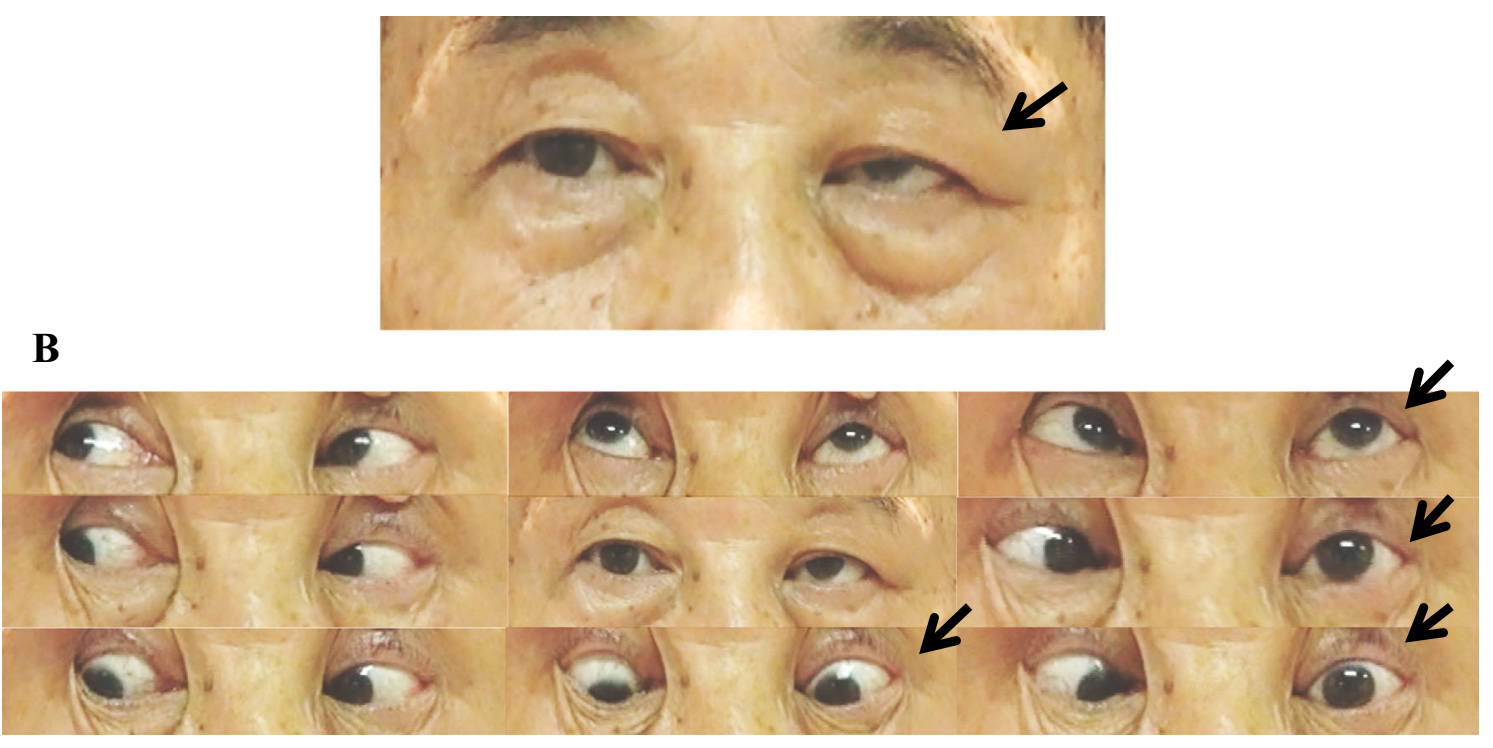

Figure 1. Eyelid swelling (A, arrow), blepharoptosis, and restricted ocular movement at lateral and inferior gaze in the left eye (B, arrows) in the present case.
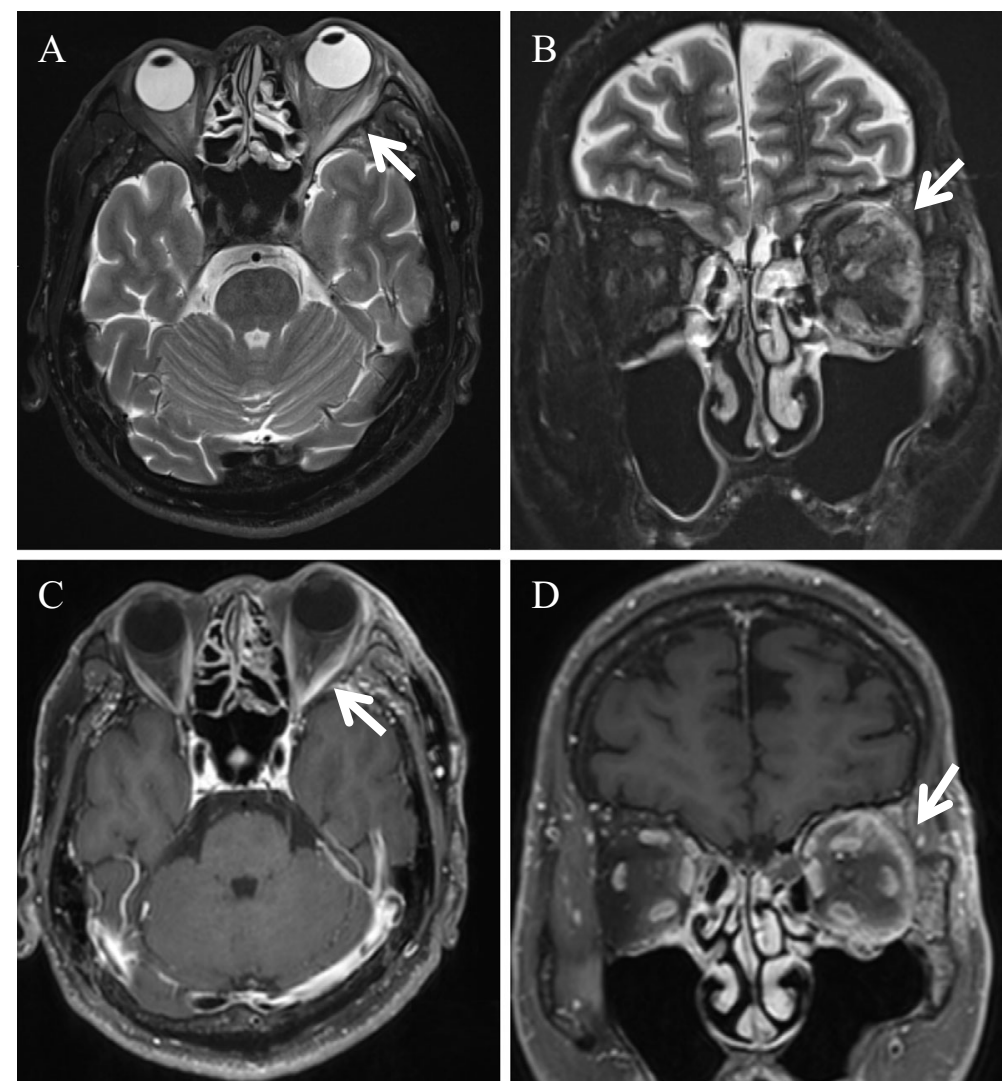

Figure 2. Cerebral short tau inversion recovery magnetic resonance imaging of the present case showed a high-intensity area in the left orbital periosteum (A and B, arrows). This lesion was enhanced after gadolinium injection ( $\mathrm{C}$ and $\mathrm{D}$, arrows).

segment, and fundus examinations were intact in both eyes. Other neurological findings were all normal. An edrophonium test did not improve his blepharoptosis or ocular movement. An otorhinolaryngological examination showed no evidence of sinusitis.
Repetitive nerve stimulation analyses of the right abductor digiti minimi and both orbicularis oculi muscles showed decremental responses. The patient's serum anti-AChR antibody titer was increased at $16.6 \mathrm{nmol} / \mathrm{L}$. The levels of thyroid-stimulating hormone (TSH), free thyroxine, free tri- 


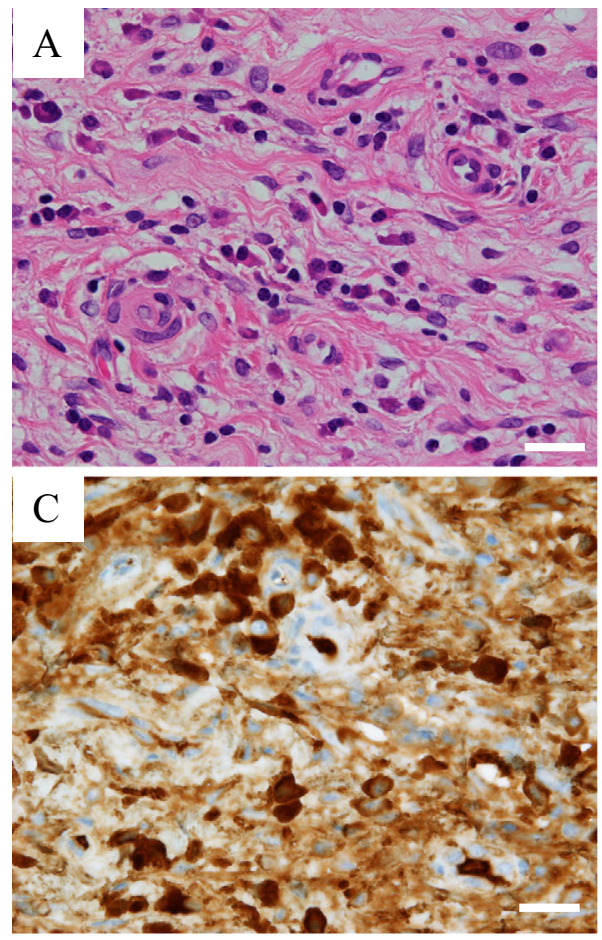

E

E
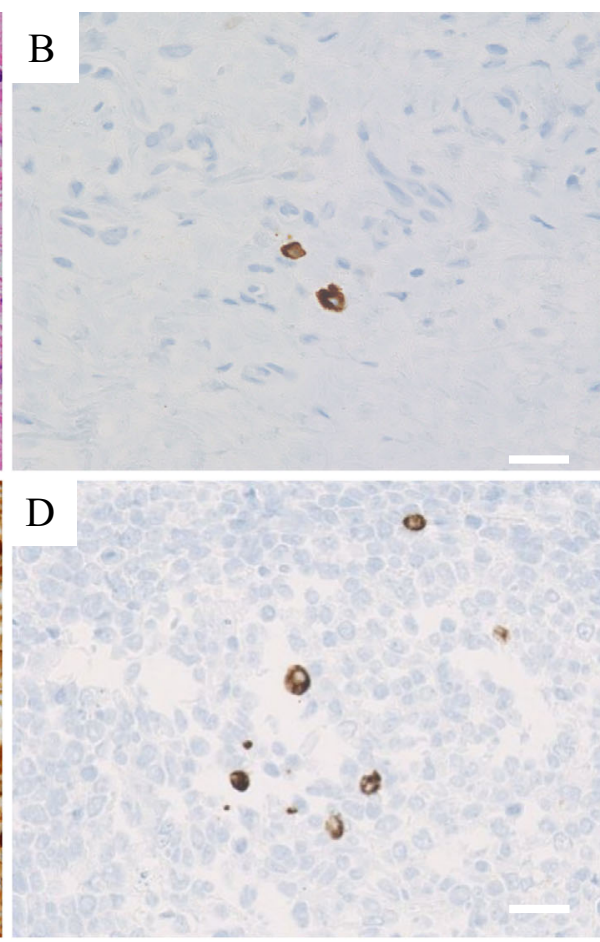

Scale bar: $30 \mu \mathrm{m}$

IgG4-positive cells against the background cells

IgG-positive cells against the background cells

IgG4-positive cells against IgG-positive cells

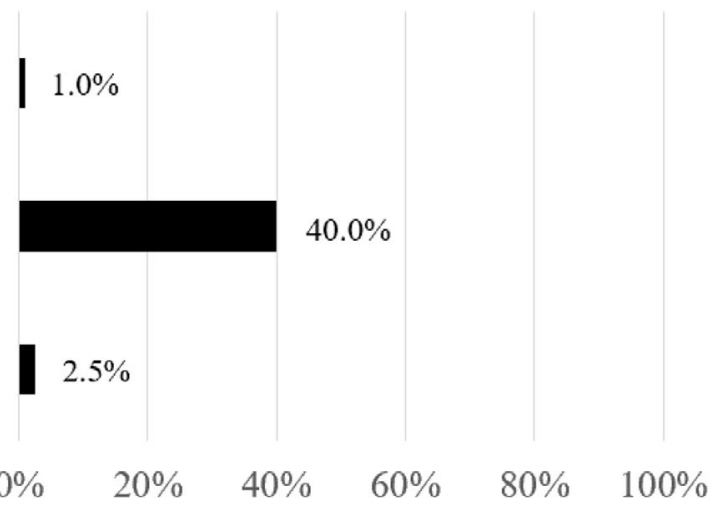

Figure 3. Microscopic findings of the biopsy specimen revealed nonspecific lymphocytic infiltration with fibrosis (Hematoxylin and Eosin staining) (A). The proportion of IgG4-positive cells among background cells was estimated to be $\mathbf{1 . 0 \%}$, and the IgG4-positive plasma cell count was 2 cells per high-power field (B). The proportion of IgG-positive cells among background cells was estimated to be $40.0 \%(\mathrm{C})$. The proportion of IgG4-positive cells among IgG-positive cells was estimated to be 2.5\% (B and C). A lymph node tissue specimen from a control subject was used as a positive control (D). Graphs of the proportions of IgG4-positive or IgG-positive cells among background cells, and IgG4-positive cells among IgG-positive cells are shown $(\mathbf{E})$.

iodothyronine, immunoglobulin G4 (IgG4), and angiotensinconverting enzyme were normal. Tests for antinuclear, antiSSA, anti-SSB, anti-myeloperoxidase-antineutrophil cytoplasmic, anti-proteinase3-antineutrophil cytoplasmic, and anti-TSH receptor antibodies were all negative. The patient's antithyroid peroxidase antibody level was $20.2 \mathrm{U} / \mathrm{mL}$ and his anti-thyroglobulin antibody level was 1,600 U/mL. All other laboratory data were normal. An ultrasound examination revealed no thyroid enlargement. Chest computed tomography revealed no thymoma.
Cerebral short tau inversion recovery magnetic resonance imaging (MRI) revealed a high-intensity area in the left orbital periosteum (Fig. 2A, B). This lesion was enhanced after gadolinium injection (Fig. $2 \mathrm{C}, \quad \mathrm{D}) .{ }^{18} \mathrm{~F}-$ fluorodeoxyglucose positron emission tomography revealed no increased uptake in the left orbital or other body areas. A needle biopsy was performed, and Hematoxylin and Eosin staining revealed nonspecific lymphocytic infiltration with fibrosis (Fig. 3A). Immunostaining was performed with a standard procedure using anti-IgG4 antibody as the primary 


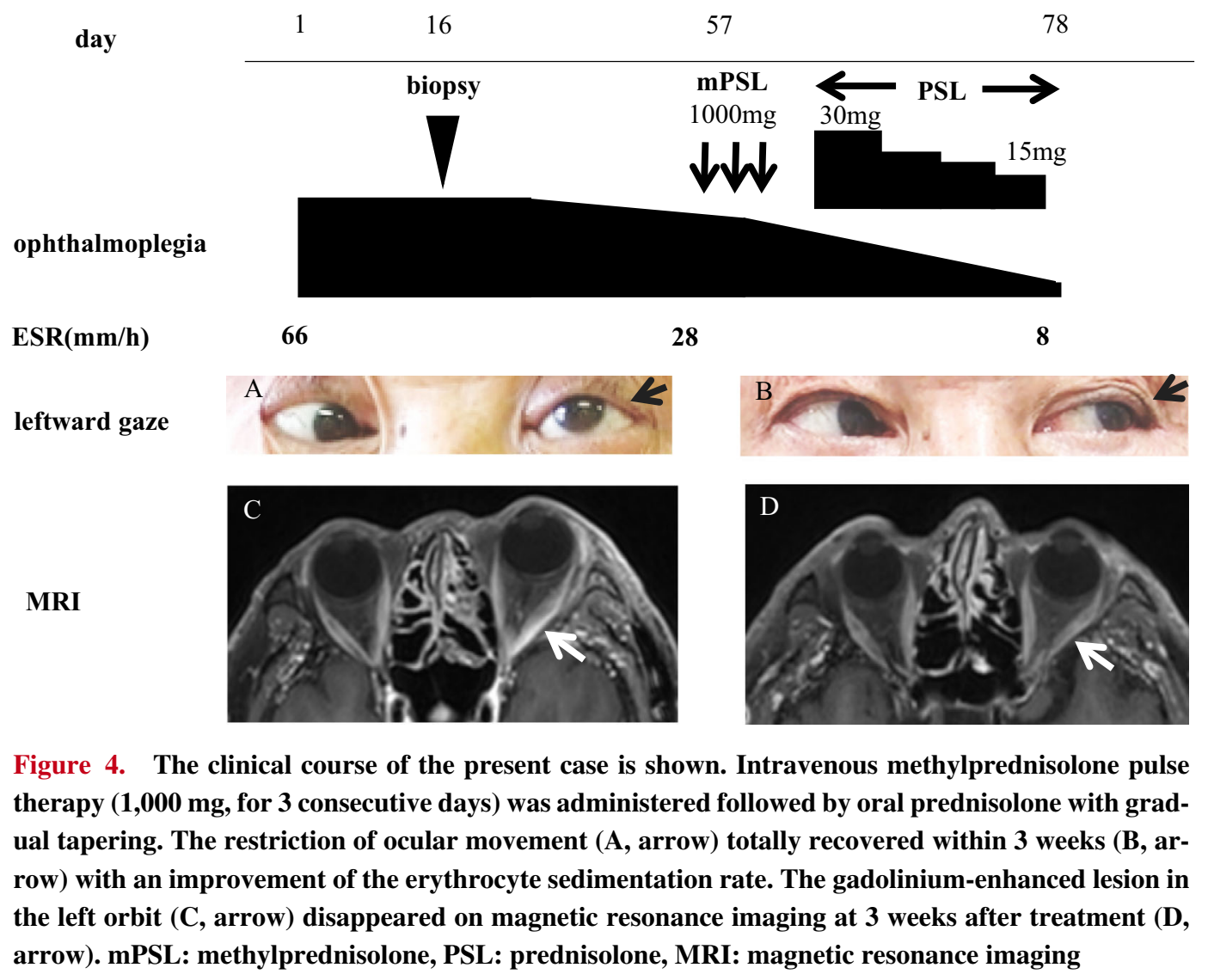

antibody, and visualized by the avidin-biotin complex method. The proportion of IgG4-positive cells among background cells was estimated to be $1.0 \%$, while 2 IgG4positive plasma cells were observed per high-power field (Fig. 3B). The proportion of IgG-positive cells among background cells was estimated to be $40.0 \%$ (Fig. 3C). The proportion of IgG4-positive cells among IgG-positive cells was estimated to be $2.5 \%$ (Fig. 3B, C). A lymph node tissue specimen from a control subject was used as a positive control (Fig. 3D). Graphs of the proportions of IgG4- or IgGpositive cells to the background cells, and of IgG4-positive cells to IgG-positive cells are shown (Fig. 3E). IgG4-related disease was excluded, and the patient was finally diagnosed with IOI. Intravenous methylprednisolone pulse therapy (1,000 mg, for 3 consecutive days) was administered followed by oral prednisolone with gradual tapering. His ocular symptoms showed a complete improvement within 3 weeks, and the gadolinium-enhanced lesion in the left orbit disappeared on MRI at 3 weeks after the initiation of prednisolone treatment (Fig. 4).

\section{Discussion}

In this report, we presented the case of a patient with MG who subsequently developed IOI, in which the origins of the patient's ocular symptoms were difficult to distinguish. Our search of the relevant literature revealed three cases of combined MG and IOI. Two cases were categorized as oculartype MG, and the MG and IOI symptoms were predomi-

nantly observed on the same side (3-5) (Table). In the present patient, the main inflammation was observed at the orbital periosteum, a finding that was not described in the previous reports. However, the co-occurrence of MG and inflammatory myopathy was described in the previous reports (6). The mechanism underlying these two disorders is unknown; however, an autoimmune process is suspected. Since the ocular symptoms due to MG and IOI in our case occurred on the same side, it is suggested that preceding autoimmune response at the neuromuscular junction may have caused the inflammation of the external ocular muscles and the orbital periosteum (7).

IOI is a benign inflammatory condition that is confined to the orbit (8). The etiology of IOI is so far unknown; however, infectious, autoimmune, or aberrant wound healing process was proposed as the potential pathogenesis (8). Concurrent autoimmune disorders such as Crohn's disease and ankylosing spondylitis have been reported in association with IOI (8). Furthermore, the presence of circulating antibodies against ocular muscle antigens in patients with orbital myositis (9), and high levels of inflammatory cytokines in IOI patients have been reported (10).

MG is an autoimmune disorder affecting the skeletal muscle endplates. The pathogenic roles of antibodies against AChR, muscle-specific kinase, or lipoprotein receptor-related protein 4 are suggested to be involved in MG (2). A subset of MG patients with thymoma have pure red cell aplasia or myocarditis due to the involvement of cell-mediated immunity. MG patients have an increased risk of developing com- 
Table. Clinical Summary of Cases of Myasthenia Gravis Complicated by Idiopathic Orbital Inflammation.

\begin{tabular}{|c|c|c|c|c|c|c|c|}
\hline Reference & $\begin{array}{c}\text { Age } \\
\text { (years) }\end{array}$ & Sex & $\begin{array}{c}\text { MG } \\
\text { subtypes }\end{array}$ & $\begin{array}{l}\text { Anti } \\
\text { body }\end{array}$ & Affected side & Treatment & Outcome \\
\hline This case & 70 & Male & Ocular & AChR & $\begin{array}{l}\text { *Ipsilateral } \\
\text { (left side) }\end{array}$ & Prednisolone & Remission \\
\hline 3) & 26 & Female & Ocular & AChR & $\begin{array}{l}\text { *Ipsilateral } \\
\text { (left side) }\end{array}$ & Prednisolone & Remission \\
\hline 4) & 55 & Female & Ocular & None & $\begin{array}{l}\text { MG: both sides } \\
\text { IOI: right side }\end{array}$ & Pyridostigmine & Remission \\
\hline 5) & 14 & Female & Unknown & None & Unknown & Radiotherapy & Remission \\
\hline
\end{tabular}

* "Ipsilateral" indicates that IOI appeared on the side predominantly affected by MG.

MG: myasthenia gravis, IOI: idiopathic orbital inflammation, AChR: acetylcholine receptor

plicating autoimmune diseases-most commonly autoimmune thyroid disease, systemic lupus erythematosus, or rheumatoid arthritis (11).

The present case suggested that IOI can occur as a complication in patient with MG, and the ocular symptoms derived from IOI can be easily misdiagnosed as symptoms due to preceding MG. Orbital pain, eyelid swelling, and orbital MRI abnormalities are characteristic findings that are useful for discriminating IOI from MG.

The authors state that they have no Conflict of Interest (COI).

\section{Financial Support}

This study was supported by Grants-in-Aid for Scientific Research (C) from the Ministry of Education, Culture, Sports, Science and Technology, Japan (grant number 19K07813) (to Y.I.), and Grants-in-Aid from the Research Committee for Ataxic Disease from the Ministry of Health, Labour and Welfare, Japan (to Y.I.).

\section{References}

1. Mombaerts I, Bilyk JR, Rose GE, et al. Consensus on diagnostic criteria of idiopathic orbital inflammation using a modified Delphi approach. JAMA Ophthalmol 135: 769-776, 2017.

2. Gilhus NE. Myasthenia gravis. N Engl J Med 375: 2570-2581, 2016.

3. Sharudin SN, Govindasamy G, Mohamad NF, Kanesalingam R, Vasudevan SK. Ocular myasthenia gravis and idiopathic orbital in- flammatory disease: double the trouble! Can J Ophthalmol 53: e55-e58, 2018.

4. Van de Mosselaer G, Van Deuren H, Dewolf-Peeters C, Missotten L. Pseudotumor orbitae and myasthenia gravis. A case report. Arch Ophthalmol 98: 1621-1622, 1980.

5. Blodi FC. Orbital pseudotumor with thrombocytopenia and myasthenia (author's transl). Klin Monbl Augenheilkd 170: 397-400, 1977(in German, Abstract in English) .

6. Ikeda Y, Tanaka M, Mizushima K, Okamoto K. A case of eosinophilic polymyositis complicated by myasthenia gravis. Muscle Nerve 21: 1356-1358, 1998.

7. Nakano S, Engel AG. Myasthenia gravis: quantitative immunocytochemical analysis of inflammatory cells and detection of complement membrane attack complex at the end-plate in 30 patients. Neurology 43: 1167-1172, 1993.

8. Yesiltas YS, Gunduz AK. Idiopathic orbital inflammation: review of literature and new advances. Middle East African J Ophthalmol 25: 71-80, 2018.

9. Atabay C, Tyutyunikov A, Scalise D, et al. Serum antibodies reactive with eye muscle membrane antigens are detected in patients with nonspecific orbital inflammation. Ophthalmology 102: 145153, 1995.

10. Mombaerts I, Goldschmeding R, Schlingemann RO, Koornneef L. What is orbital pseudotumor? Surv Ophthalmol 41: 66-78, 1996.

11. Nacu A, Andersen JB, Lisnic V, Owe JF, Gilhus NE. Complicating autoimmune diseases in myasthenia gravis: a review. Autoimmunity 48: 362-368, 2015.

The Internal Medicine is an Open Access journal distributed under the Creative Commons Attribution-NonCommercial-NoDerivatives 4.0 International License. To view the details of this license, please visit (https://creativecommons.org/licenses/ by-nc-nd/4.0/).

(C) 2020 The Japanese Society of Internal Medicine Intern Med 59: 1763-1767, 2020 